International Journal of Engineering \& Technology, $7(2.7)(2018) 436-440$
SPC
Website www.sciencepubco.com/index.php/IJET
Research Paper

\title{
Smart Homes: Steps, Components, Utilities and Challenges
}

\author{
Velivela Gopinath*, Arigela Srija ${ }^{2}$, Dr S Krishna Rao ${ }^{3}$, Avula Madhuri ${ }^{4}$ \\ ${ }^{1}$ Assistant professor \\ ${ }^{2}$ Prefinal Year Student \\ ${ }^{3}$ Professor, Head of Department,IT \\ ${ }^{4}$ Prefinal Year Student \\ *Corresponding author E-mail:velivela.gopi@gmail.com
}

\begin{abstract}
Smart Home is a flourishing technology of $20^{\text {th }}$ century. It integrates of many new technologies through home networking for improving quality of human's life. Intelligent Home trade has drawn goodish attention of researchers for quite a decade. Smart Home technology is a combination of network and services and much more consequently, this paper focuses on various topics in smart home technologies from surveying for smart home research projects and presents a survey of all such systems and covers advantages of smart home systems, smart steps and simple components to install smart homes. So, the presented paper can be cookbook of ideas for who ever want to learn this blossoming technology.
\end{abstract}

Keywords: Smart Home, Sensors, Smart Home Appliances, Home Automation and Smart Home Technologies.

\section{Introduction}

When we assembled a collection of smart devices under one roof, and we facilitate them to connect to and commune with one another, what we end up with is typically called the "Smart Home".Some people call it home automation, because all of your smart devices work in concert to auomate a diversity of household chores and operations. When the electronic gadgets are plugged in, but not in use ,still there is a some amount of electricity flow.Here there is consumption of resources.Moreover there is a chance of short circuits.To reduce this type of problems we have an move towards implementing a technology called Smart Homes [14].

The concept of development of a smart home system is not an isolated case it has been existed since the term "smart house" was first coined by the American Association of House builders in 1984 [11]. The main desirability of any automated system is tumbling human labor, effort, time and errors due to human abandon. Smart phones have become a necessity for every single person on this sphere. Smart home automation is not about controlling the lights, fans and motors. Of course, it is about that, but it' $s$ analyzes the data that is collected from sensors, machines and humans and do according to the automating functions along with controlling energy saving functions [2]. It provides comfort, security to the user. With the increase in consumption of energy and population, there is a grave need to conserve energy in every way possible. So, the implementation of Smart Home Technology is to be finest. Implementation of these systems will not just increase the comfort level of modern generation but also help elderly and physically disabled people [1] [13]. All researchers are trying to put some handheld device (e.g. mobile or some battery-operated device) in hand on people to increase level. Home needs three gears to brand it as smart:

1. Inter-Networking tools like wires, cables, and wireless

2. Smart controlling devices like gateway to manage the featured systems.
3. Home automation - products within the home and associations to services and systems outside the home [4].

In smart home system design,it employs microcontrollers to monitor ovens,refrigerators, washing machines, lighting and VACH facilities (Ventilation/Air-Conditioning/ Heating) with respect to temperature or humidity and to regulate consequently to meet the home owner's necessities[3]. Consequently, it is noticeable that home automation has some extent to take accountable for the indoor energy management and supervision with the directions of domiciliary owners. The computer which is user-friendly and seamless control unit in the household enviornments[1].Today's home automation systems are more probable to dispense programming and monitoring control among a devoted device in the home, like the control panel of a security system, and a user-friendly application interface that can be get into via an Internet-accessble PC, smartphone or tablet[5]. The system which accomplishes the connected thermostat and smoke alarm to create a two-way association with the users where both benefit and communicate each other. So it even sound like a "acquainted home."

\subsection{Advantages}

There are so many advantages for having a smart home. some are mentioned below.

\subsubsection{Convenience}

The principal assistance of smart home technology is that of Convenience; by programming basic actions, don't have to be anxious with them. A smart Home is further convenient than a regular Home. The capability to governor the whole thing in your home from your Smartphone or computer-or to have the whole thing 
prompted inevitably based on constraints set in development. It's an tempting panorama.

\subsubsection{Security}

Smart home security systems add a lot more options to this type of basic systems such as webcams throughout the house that can monitor from your smart phone or computer. It goes beyond burglar alarms. There's the security of knowing that everything in a house is working correctly or not.

\subsubsection{Efficiency}

Smart Home knows about more than human about saving energy. Automatic lighting turns on and off not only in response to the amount of light outside, but also to whether there's anyone actually in the room or not. Smart appliances are scheduled to run when energy rates are their lowest and not at all when water or electricity are scarce. Some lights are even programmed to operate at a slightly lower wattage than normal, so that one can save energy without even knowing it.

The residual contents of the paper is prearranged as follows.Unit 2 describes the smart steps to smart home, unit 3 describes the simple components for a smart home,unit 4 includes the automation of a smart home,unit 5 describes the popular smart home projects,unit 6 describes the challenges to design a smart home and final unit concludes the paper.

\section{Smart steps to a Smart Home}

The systematic development of smart home is very complex. There are six steps to develop a smart home.

\subsection{Basic Communications}

The first step in creating a smart home is enabling members of the household to communicate with other people outside the home Basic to achieving this step is some sort of communications technology, ranging from landline telephone service to mobile phone service to broadcast television reception to an internet connection. It enables data communication in addition to voice communication.

\subsection{Simple Commands}

Ability to issue some sort of commands to perform basic operations like locking or unlocking a door, turning lights on or off, checking for mail, even summoning helps when someone falls and can't get up. In this step, the house will also respond to commands from outside the home.

\subsection{Automating Basic Functions}

In this step, manual control gives way to automatic control, via programmed instructions through a smart application. One can check the needed groceries are there in the refrigerator for make a dish, check the conditions of electric appliances and which are controlled by a remote.

\subsection{Tracking and taking Actions}

In this step, a home can act on unusual data from sensors throughout the house. It uses programmed algorithms or basic artificial intelligence to make decision based on the data. For example, the car has a repair and it finds and sends the data to mechanic so that he has to come and repair the car and make car ready to the owner. Camera is the monitoring device which is used for tracking the actions.

\subsection{Prompting Activities and Answering Questions}

Here the system prompt the activities based on the requirement which intern have the intelligent system. An individual that keep questioning the system and getting answers like "What appointments do I have today?"

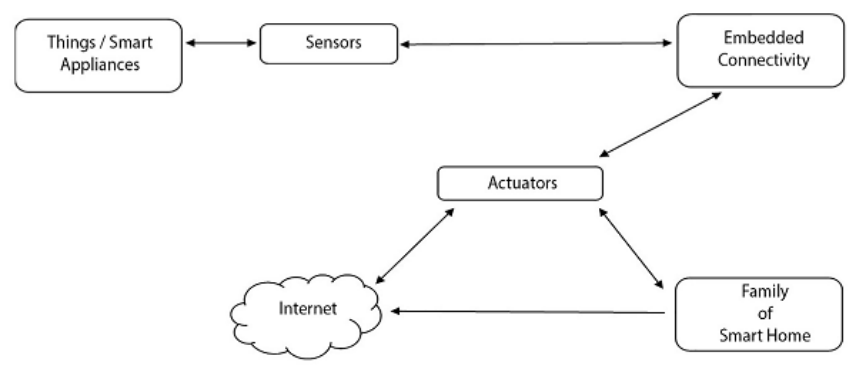

Fig 1: Working of smart home things

\subsection{Automating Tasks}

Home system will automatically schedule necessary maintenance and repairs for all its component pieces and parts, recorder medications before anyone can run out, prepare grocery lists, run the robotic vacuum cleaner and do anything automatically. It is appropriately wired and necessarily informed, making its own decisions, and performing all manner of menial and important tasks.

\section{Simple components for a Smart Home}

There are so many components involved in designing a smart home. Then number of components depends on the complexity and features used in smart home.

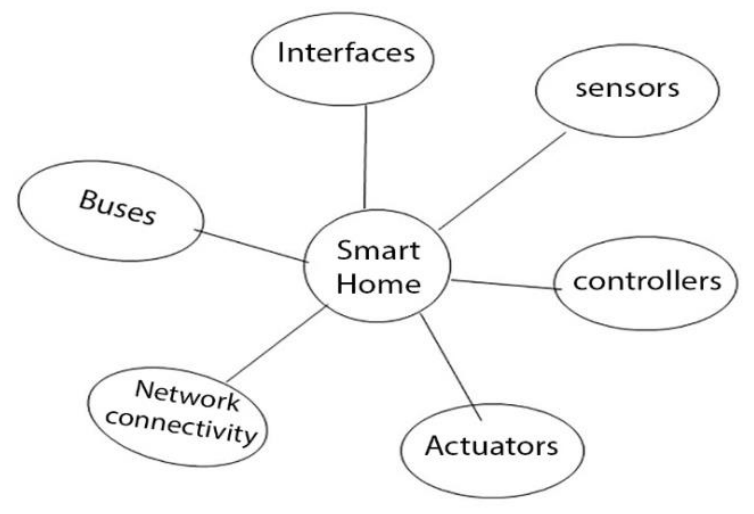

Fig 2: Components of Smart home

\subsection{Buses}

A bus is the communication system that transfers data between devices, in a smart home. Different types of buses transfer data according to different protocols; for devices within the home to communicate with one another, they must all be compatible with the same bus type.

\subsection{Interfaces}

An interface enables the communication between different devices or between humans and devices. In device-to-device communication, the interface is just a digital protocol. In the case of human- 
to-device communication, the interface typically includes some sort of controller and display, so that the person doing the controlling can see what he is doing.

\subsection{Sensors}

Sensors are used to determine the status of our environment and of various devices. To detect temperature, humidity, light, noise and motion. Specialized sensors detect smoke and carbon monoxide levels; proximity sensors detect doors and windows are open or shut. They can also detect status of devices and location of devices and people and so on.

Table 1: List of sensors and purposes

\begin{tabular}{|l|l|l|}
\hline S. No & \multicolumn{1}{|c|}{ Sensor } & \multicolumn{1}{c|}{ Purpose } \\
\hline 1 & Light Sensor & Measures the intensity of light. \\
\hline 2 & PIR Sensor & Identifies the user position. \\
\hline 3 & $\begin{array}{l}\text { Temperature } \\
\text { Sensor }\end{array}$ & $\begin{array}{l}\text { Measures the room temperature and } \\
\text { body temperature periodically. }\end{array}$ \\
\hline 4 & Pressure Sensor & Measures the pressure of gases or liquids. \\
\hline 5 & Switch sensor & Detection of Door open or close status. \\
\hline 6 & RFID Sensor & identification of Object and people \\
\hline 7 & $\begin{array}{l}\text { Ultrasonic Sen- } \\
\text { sor }\end{array}$ & Tracking of Location \\
\hline 8 & Current Sensor & Measures the usage of current \\
\hline 9 & Power Sensor & Calculates the usage of power \\
\hline 10 & Water Sensor & Measures the volume of water usage. \\
\hline
\end{tabular}

\subsection{Actuators}

An Actuator is stereotypically a mechanical or electrical device that triggers a given bustle. Like motors and switches. Such as those in electric light switches, motorized valves, and the like Deprived of actuators, nothing gets done. Examples are home doors, window draperies, garage door openers and closers, windows, involuntary light switches etc[10].

\subsection{Controllers}

These are necessary to send signals to other devices to initiate some sort of operation or be a part of a larger device to control multiple devices [9]. High-end full house systems are shaped by traders such as Crestron controller and Control4 controller and low-end systems a like X10.

\subsubsection{Crestron:}

It offers a variety of smart home devices, to control TV and music playback, lighting, window treatments, temperature, door locks and other home security. With everything connected to Crestron's main hub, one can press one button on a remote or Smartphone app to enable a specific "scene."

\subsubsection{Control4:}

It supports a number of smart devices from other manufacturers and also offers its own line of devices. These include touch screen Controllers, wall keypads, multi-zone audio amplifiers, light switches and dimmers, smart thermostats, and the like. To communicate with connected devices, the control4 system uses either TCP/IP over the internet or Zigbee's wireless mesh networking technology.

Note: homeseer, iris, mcontrol, quirky, Wera, vivint, vemo, wink are other type of controllers.

\subsubsection{X10:}

$\mathrm{X} 10$ is grand daddy of them all. It operates over your home's existing power lines. Just connecting to an electrical device to an X10 Appliance module, this then plugs into a nearby wall outlet. With a similar X10 transceiver Module plugged into another outlet, use the controller to wirelessly operate any plugged-in device. It is a low- cost module.

\subsection{Networks}

All the communication within the home takes place over some kind of network, either wired or wireless. In wired network the paraphernalia is fitted to the walls and associated to main power supply, so that the data will spreads to activate or deactivate the purposes of things. Wired home automations are associated using optical fiber, twisted pair, power line, bus line etc. One of the owing technologies is X10 which cost is very low and it is an open standard. That is communication of binary data using the Amplitude Modulation (AM) procedure. Most home automation today is done wirelessly, using Wi-Fi, Bluetooth, or similar proprietary networking technologies.

\subsubsection{INSTEON:}

It is a leading developer of networking technology for the connected home. Its devices connect via a combination of wireless radio frequency and wired power line technologies. Insteon's RF networking operates in a mesh configuration. Because of the way mesh networks work; Insteon systems have no need for a central controller. Setting up an INSTEON system is as simple as plugging each device into a special power connector. This is automatically connecting the new devices to all existing devices in a home.

\subsubsection{Z-WAVE:}

It is a wireless technology operates in the $900 \mathrm{MHz}$ band.It's a low-energy technology, so Z-wave devices can operate on battery power alone. A single Z-wave network can handle up to 232 devices, with an average maximum range between devices of 300 feet and so on.

\subsubsection{ZIGBEE:}

It works similar to Z-wave and is supported by similar number of home automation companies. It operates in the $915 \mathrm{MHz}$ band. The mesh configuration enables a 30 to 60 foot connection range between devices. It is incorporated into tens of millions of smart gas and electricity meters ideaa.

\section{Automating the Home}

A typical home composes of kitchen, living room and bed room. To design a smart home, one must discriminate the each and every function of kitchen, living room and bed room.

\subsection{Kitchen arena}

The most things or smart appliances found in kitchen like smart refrigerators, micro ovens, dish washers, coffee makers etc. If a person has wake-up routine at morning and take a coffee. In this case, the automatic alarm rings, the coffee maker makes coffee and gives an alert to user that his coffee is ready [6]. The smart refrigerator tells about the food he/she take (about diet and inhale 
of calories), the groceries are to be needed and gives a quick link service to the vendor who brings all the groceries.

\subsection{Living room arena}

The smart TV will explore over the entertainment one is interested. The smart TV will have numerous purposes like desktop personal computer. So, this leads to interactive TV and added interactive content will turn out to be accessible.

\subsubsection{Smart Living with Smart Furniture:}

The furniture has in-built mirror technology which makes the user so excited and make he/she satisfied.

\subsubsection{Smart Environment with smart Lightning:}

The lights which work smarter, as they maintain their brightness according to the daylight and gets switch off when someone leaves the room. By giving the good lightning, ventilation that satisfies the user.

\subsubsection{Smart Living:}

The camera detects and informs to the household owner that the guests are arrive with a face detection technology and makes all the services get prepared to the guest by tracking and analysing all the guest data.

Table 2: Utilities and services of smart home

\begin{tabular}{|c|c|c|}
\hline Category & Services & Function \\
\hline Ease & $\begin{array}{l}\text { To provide com- } \\
\text { fort }\end{array}$ & $\begin{array}{l}\text { Lighting, controlling the tem- } \\
\text { perature. Arrange the home } \\
\text { environment according to the } \\
\text { inhabitant's wish. Home appli- } \\
\text { ance controls the its very com- } \\
\text { fort to identification of intro- } \\
\text { duction, presentation, game and } \\
\text { siesta TV program selection, } \\
\text { cooking recipe presentation and } \\
\text { elapsed possessions facility [8]. }\end{array}$ \\
\hline $\begin{array}{l}\text { Remote } \\
\text { Access }\end{array}$ & $\begin{array}{l}\text { Remote access, } \\
\text { monitoring and } \\
\text { control }\end{array}$ & $\begin{array}{l}\text { Appliance monitoring and } \\
\text { control through mobile devices } \\
\text { and computers from remote } \\
\text { location, Appliance monitoring } \\
\text { and control over web browser } \\
\text { from distant location. }\end{array}$ \\
\hline Home Automation & $\begin{array}{l}\text { Automate Home } \\
\text { appliances con- } \\
\text { trol }\end{array}$ & $\begin{array}{l}\text { Voice-operated(speech) appli- } \\
\text { ance control, Intelligent appli- } \\
\text { ances monitoring and control- } \\
\text { ling. Optimization of energy. } \\
\text { Conservation of energy. Reduc- } \\
\text { tion of Energy Wastes. }\end{array}$ \\
\hline Healthcare & $\begin{array}{l}\text { Wellness } \\
\text { monitoring }\end{array}$ & $\begin{array}{l}\text { Graphical illustration of well- } \\
\text { ness, Respiratory and sleeping } \\
\text { disorder valuation. } \\
\text { Activity tracking and alarm } \\
\text { Generation system, Sleeping } \\
\text { stage appreciation process. }\end{array}$ \\
\hline
\end{tabular}

\subsection{Bedroom arena}

The room has nifty climate control which the users can customize the scene in bedroom through single-touch heating system and can pick an inimitable night-time temperature and illumination silhouette for each and every bedroom. The bed is also fortified with sensor that can monitor movement of a person in bed for perceiving health condition concerning sleeping in emblematic tedious of human beings.
Smart homes afford services and utilities to enhance user necessities. One of the chief purposes of smart homes is the optimization of user luxury by tumbling communications between the occupant and home devices [3]. Smart homes can able to control the basic ecological constraints such as light, temperature and heat. Home appliance monitoring and control from isolated places is a widespread service that can effortlessly be provided via smart homes. Smart home technology has attained substantial developments in the field of healthcare industry, such as patient monitoring, telemedicine, and wellness nursing. Healthy people should be anxious about their wellness and take safety measures in contradiction of illness [5]. Self-monitoring systems vividly assess the wellness disorder of the inhabitant.

Furthermore, the smart devices are used in numerous facets, for instance,

\section{Welfare industry:}

Health monitoring, personal trainer, remote diagnosis

\section{Entertainment field:}

Television, video, games, Smart Home Theatre, Multi-Room Audio, HD Video Distribution

\section{Environment facet:}

Remote controlling of light, heat and air conditioning.

\section{Security field:}

Smart Security, simulated habitation, assets monitoring and protection, exposure of fire, gas leaks and water leaks tale- aid.

\section{Communication facet:}

Video phone, home calendar, prompts and communiqué inside and outside the house.

\section{Go Green facet:}

Reduce Electricity and heating fuel consumption.

If a person goes on vacation, he simply doesn't worry about his home because he wants to monitor and controls everything he needed in his house from outside [7].

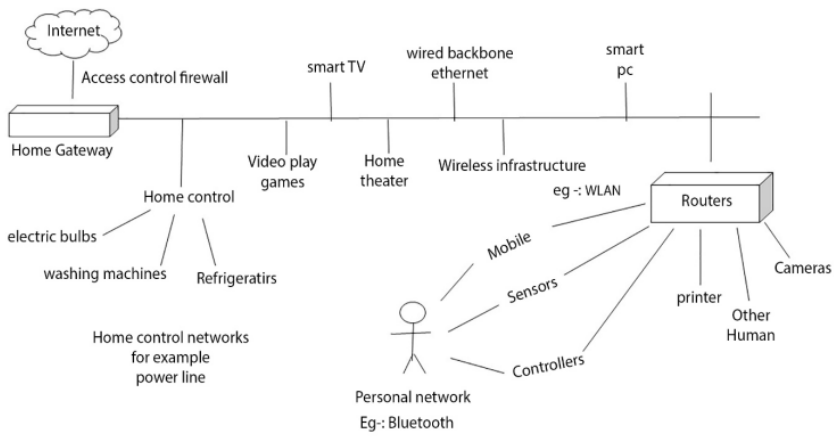

Fig 3: Smart home networks

\section{Smart Home Projects}

Smart Home technologies are being developed by various usages of new and tremendous technologies. Due to rapid growth in Technology, Bluetooth has brought a revolutionary change. Various smart projects are developed based on Bluetooth which is a low cost and affordable. Another type of low cost technologies is Z-wave and ZigBee. Smart homes are all about efficient usage of available resources [12]. For this reason, various energy efficient renewable resources projects have been developed. With the aggregation of clod-computing, there are so many cloud- based smart home projects are developed which are extensible and provides many applications like entertainment, ecological, security systems, domestic purposes, information systems, communication and healthiness systems.

Another project is that the Computer-aided design CAD/CAM software for smart home device. The software is developed based on cloud computing facility project. It helps the designer to choose a smart home device and design and develop a smart living space 
[12]. This project offers pictorial simulation by smearing the interface to construct a real smart home. The procedure of smart home device has four smart triggering modes including passive, responsive, active and interactive. Consequently, it is much more obliging in make financial arrangements and estimates.

In Egypt, a project was developed for the purpose of energy saving. The project titled as 'Energy saving through smart home'. The project aims to utilize the sensors to diminish the native energy waste. One more project was done by Kong national university. Smart home energy management system using IEEE802.15.4 and Sigsbee [12] [13] is developed. It was developed to control the smart home based on Energy savings and user cheerfulness, which are two focal design considerations. In this system, they eradicate the wires from the lighting panels. so that it offers further assistances, together with better and substantial savings in setting up by avoiding the expense and distraction of electric wiring.

Besides, there is adaptation of the smart technology in various aspects of home utilities. Such a venture is developed and named as Calendar oriented services for smart home [1]. This project is the extension of service model built on home calendar to support ambient intelligence in home, subsequently the service will deliberate the family activities forecasting and afford added intelligence, and supplementary smart vision of the smart Home.

\section{Challenges}

There are so many challenges to design a smart home. Basically, the following are the common challenges for developing a smart home.

\subsection{Security:}

Almost all smart homes are associated through the Internet 365 days. This consents an intruder to be anyplace in the biosphere and can still be pointing the home. Furthermore, an intruder may easily cherry pick the instant of occurrence.

\subsection{High cost:}

Because of the adaption and installation of smart devices which are having high advanced technology, it takes high cost for implementing Smart home technology.

\subsection{Device Compatibility:}

Home automation systems typically comprise of devices belongs to diverse manufacturers or development industries. Each and every device comes up with its own liabilities. Each device is assembled in our place. But almost all individual parts come from different companies. Likewise, home inhabitants who are not professionals on networking or security do the upgrade or reconfiguration of their own home networks, disparate researchers do in the labs, which fetches in its peculiar set of liabilities.

\subsection{Big Data:}

Due to erroneous generation of data, data management is challenging issue. The journey of big data from $3 \mathrm{Vs}$ to $9 \mathrm{Vs}$ is illustrated [15].

\section{Conclusion}

The paper mainly focuses on the major steps to develop a smart home and components needed to design a smart home. There are six steps to a design a smart home like basic communication, simple commands, automating the basic functions, tracking and taking the actions, prompting activities and answering questions and automating the tasks. The main components of a smart home are buses, interfaces, sensors, controllers, actuators and a network. The study illustrates that some typical smart home automation modules can be discriminated by kitchen, living room and bed room. Each module has its own utilities and services to be implemented. The study includes the three best smart home projects in the world. There are so many challenges in designing a smart home like security, cost, device compatibility and data flood.

Here and now smart home is more than just a home, controlled by the essential assessment unit like a mobile, tablet, handheld devices and computer. The quality of human life will obviously be increased through the smart home technology. Through the smart home, humans get more comfort in accessing home essentials. Nevertheless, smart home technology is a decent choice for inhabitants who care about security, comfort and energy savings.

We conclude that the smart homes are the future homes. We expect that a typical home is constructed by bricks, cement and sand but in future bricks, cement and sand may be one of the smart home devices or sensor or fully replaced by other devices.

\section{Acknowledgement}

The efforts were directed and supported comparatively by management \& principal of sir c r reddy college of engineering, eluru, a.p, and India.

\section{References}

[1] Meensika S, Xuanxia L, Ponchan $\mathrm{P}$ and Mahasak Ketcham Research and Thinking of Smart Home Technology in International Conference on Systems and Electronic Engineering December 18-19, 2012 Phuket.

[2] B. Brumitt, Meyers, Krumm,Kern, S. Shafer, "EasyLiving: technologies for intelligent environments", in Proc. 2nd Int. Symposium on Handheld and Ubiquitous Computing, 2000, pp. 97-119.

[3] Internet of Things by Miller Michael.2015 edition

[4] Jackie Craven, "What Is a Smart House?" [Online], Available:http://architecture.about.com/od/buildyourhous1/g/smarthous e.htm. [2012, October 18].

[5] Saisakul Chernbumroong,Anthony Atkins and Hongnian, 2010, "Perception of Smart Home Technologies to Assist Elderly People", The 4th International Conference on Software, Knowledge, Information Management and Applications (SKIMA 2010), Paro, Bhutan, pp. 1-7.

[6] Li Jiang, Da-You Liu and Bo Yang, "Smart Home Research", 2004, Proceedings of the Third International Conference on Machine Learning and Cybernetics, August26-29, Shanghai, pp. 659-663.

[7] Manfred Huber, 2006, "Smart Home Technologies Availablehttp://ranger.uta.edu/ huber/cse4392_SmartHome [2012, October 181.

[8] iT24Hrs, 2012, "Smart room, smart home" [Online], Available: http://www.it24hrs.com/2012/smart-room-smart roomautomation.[2012,October18]

[9] https://www.uniassignment.com/

[10] Sang Hyun Park, And So Hee Won, Pers Ubiquit Comput (2003) 7: pp. 189-196

[11] VLoia, S Sessa, Soft computing agents: new trends for designing autonomous systems, Physica-Verlag GmbH, Heidelberg, Germany, 2002

[12] Huang Ke-qiang,Ming-guang, Smart home based on home network, Journal of Zhejiang University (Engineering Science),Vo 1. 36 , pp. 616-620, Nov. 2002,

[13] [13] Hagras H, Colley, Callaghan, Clarke, Duman H, Holmes, A Fuzzy Incremental Synchronous Learning Technique for Embedded- Agents Learning and Control in Intelligent Inhabited Environments, IEEE International Conference on Fuzzy Systems (FUZZ-IEEE), May- 2002

[14] Reyes A, Barba A, Callaghan V, Clarke G, The Integration of Wire less, Wired Access and Embedded Agents in Intelligent Buildings, SCI 2001, The fifth World Multi Conference on Systemics, Cybernetics and Informatics, Orlando, Florida, July 2001 .

[15] V.Gopinath,ch yallamanda,k purna prakash,dr s Krishna rao, "a jour ney of bigdata form $3 \mathrm{vs}$ to $3^{2} \mathrm{Vs}$ ",IJRCCT,ISSN NO:22785841 , volume 5 , issue 3 . 